\title{
Rapid separation and extraction of radioactive analytes onto filters and surfaces
}

\author{
By E. R. Gonzáles, A. L. Klingensmith and D. S. Peterson* \\ Chemistry Division, Los Alamos National Laboratory, Los Alamos, NM 87545, USA
}

(Received November 27, 2009; accepted in revised form November 11, 2010)

Actinide / Plutonium / Separation / Analysis /

Alpha spectrometry / Sample preparation

Summary. This paper presents a radiochemical procedure that combines radiochemical sample preparation and analyte separation to provide a rapid sample preparation method. Extractive ligands are prepared in a polymer matrix. This system can be immobilized on a surface or on a filter. Filters allow rapid sample uptake due to the movement of the analyte through the filter material. These approaches offer fast uptake kinetics, high material loading, and good selectivity. These systems have been demonstrated for the rapid extraction of plutonium and americium from solution and their subsequent analysis by alpha spectrometry, with no additional sample preparation required, thus eliminating extensive wet chemical processes that would otherwise be necessary. We have evaluated the extraction efficiency that can be obtained and have shown that these systems can provide for alpha spectrometry peak widths near what can be obtained using traditional techniques such as electroplating. We have also demonstrated Polymer Ligand Films (PLFs) for the selective extraction of plutonium from a solution prepared from a soil digest.

\section{Introduction}

Radioanalytical methods for the determination of alpha emitting radionuclides are based on the separation and preconcentration of selected elements prior to radiation detection [1-3]. Standard analytical methods require sample preparation in an aqueous acidic solution. Each analyte is separated from the solution (in an ion-exchange column) and collected. The collected radioactive analyte is mounted onto a surface using a method such as electro-deposition and then counted $[4,5]$.

Counting the ligand directly after actinide extraction is the key to rapid sample analysis and isotopic determination. Other studies have shown selective extraction [6] or ion exchange [7] in thin films for non-radioactive analytes. More recent studies have demonstrated the extraction of radioactive analytes on a thin film. One approach involved grinding a commercially available extractive resin to a fine powder and fixing it to a flat surface with a binder [8]. This attaches both the extractive ligand and the support material onto a surface.

\footnotetext{
*Author for correspondence (E-mail: DominicP@lanl.gov).
}

Another method involved preparing a thin film of manganese oxide, and used it to extract radium from solution, which was subsequently analyzed by alpha spectrometry [9]. Previous approaches have limited flexibility in thin film preparation minimizing improvements and hindering the range of radionuclides that can be analyzed. Ridged constraints in the physical properties also minimize adjustments to performance improvements.

Another approach utilized a self-assembled monolayer composed of an extractive ligand to extract and concentrate actinide analytes $[10,11]$. This technique was used to analyze a variety of radionuclides. Recently, we introduced an approach of incorporating chemicals into a thin film structure to extract, pre-concentrate, and separate radioactive analytes [12]. This chemistry on a surface allows us to reduce and minimize interferences. Collecting the radioactive analytes on the surface enables the ligand surface to be directly analyzed by radiation detection equipment.

Utilization of extractant thin films of selected extractant ligands for uptake of radioactive constituents has several advantages. There are wide ranges of extractive chemistries that have been demonstrated for actinide and lanthanide analytes $[3,13,14]$. The combination of prepared thin films on a porous matrix produces materials with a large surface area and densely packed absorption sites on a surface produces a surface capable of rapid and selective extraction of radionuclides from solution. The result is a plethora of materials with rapid kinetics, high exchange capacity, and the potential for tailor-made surface chemistry interactions. One extractive ligand that has been developed and is commercially available for the extraction of actinides from aqueous solution is bis(2-ethylhexyl)methanediphosphonic acid $\left(\right.$ Dipex $\left.^{\circledR}\right)$ [15]. This extractive ligand has strong affinity for tri-, tetra-, and hexa-valent oxidation states. In addition, the uptake kinetics for actinides onto Dipex ${ }^{\circledR}$ are very high at moderate concentrations of nitric and hydrochloric acid.

In this study, three different polymer ligand substrates have been evaluated. All three involve the extractive ligand Dipex ${ }^{\circledR}$ in a polymer film. The three polymers utilized are poly(styrene) on a stainless steel planchet, nitrocellulose (utilized as a Collodion suspension) on a stainless steel planchet, and poly(vinylpyrrolidone) on a poly(propylene) filter with a pore size of $0.1 \mu \mathrm{m}$. These polymer ligand films are then used to rapidly extract americium and plutonium from solution. Once the analytes are collected, the polymer 
ligand film can be counted directly without any further sample processing required.

\section{Experimental section}

\subsection{Materials and instrumentation}

Reagents used were prepared using analytical grade chemicals. Tetrahydrofuran (THF) and polystyrene were obtained from Sigma-Aldrich (Milwaukee, WI), Dipex ${ }^{\circledR}$ extractant and the poly(propylene) filters were obtained from Eichrom Technologies Inc. (Darien, IL), and Collodion from Mallinckrodt Chemicals. Sodium nitrite, hydrochloric acid, sodium hydroxide, and nitric acid were obtained from Fisher Scientific (Pittsburgh, PA). NIST traceable plutonium-239, plutonium-242, americium-241, and americium-243 standards were obtained from Isotope Products Laboratories (Valencia, CA). These isotopes were selected so that they could be simultaneously analyzed in the alpha spectrometer without interfering with one another. Deionized water was used for solution preparation. Analyses were carried out on an Ortec (Oak Ridge, TN) Octete Plus Alpha Spectrometer. The alpha spectrometer was equipped with a $900 \mathrm{~mm}^{2}$ Passivated Implanted Planar Silicon (PIPS) solid-state detectors, which provide a counting efficiency as configured of up to $14 \%$.

\subsection{Preparation of polymer ligand films}

Three different polymer ligand films were produced in this study. In order to make the Dipex ${ }^{\circledR}$ and poly(styrene) PLF, these two compounds were dissolved in THF so the total concentration of the polymer ligand film in solution was $1: 10(\mathrm{wt} / \mathrm{wt})$. The concentration of the Dipex ${ }^{\circledR}$ and poly(styrene) were $1: 5(\mathrm{wt} / \mathrm{wt})$, relatively. The CollodionDipex $^{\circledR}$ at a ratio of $1: 20$ (wt/wt) was dissolved in isoamyl acetate at $1: 5(\mathrm{wt} / \mathrm{wt})$. In order to make the polymer ligand films on a surface, the solvent solution was added to a $40 \mathrm{~mm}$ diameter stainless steel planchet. The solution was deposited using an automated pipette $(10-100 \mu \mathrm{L})$ and the solvent was allowed to evaporate at room temperature. The PLF was further dried by placing the disk into a small drying oven set at $75^{\circ} \mathrm{C}$ for approximately $1 \mathrm{~h}$. This removed all solvent to preclude foaming when placed under vacuum for alpha counting. To prepare the PLF on a filter, poly(vinylpyrroliodone) and Dipex ${ }^{\circledR}$ were dissolved in isopropanol at a concentration of $1: 5(\mathrm{wt} / \mathrm{wt})$. This solution was deposited on a $25 \mathrm{~mm}$ diameter poly(propylene) filter with a pore size of $0.1 \mu \mathrm{m}$. The solution was allowed to dry prior to use as stated above.

\subsection{Preparation of neat solutions}

Solutions of ${ }^{242} \mathrm{Pu}$ and ${ }^{241} \mathrm{Am}$ were prepared by drying $685 \mathrm{mBq}$ of ${ }^{241} \mathrm{Am}$ and $425 \mathrm{mBq}$ of ${ }^{242} \mathrm{Pu}$ and dissolving the solution up to $2 \mathrm{~mL}$ with $\mathrm{HNO}_{3}$. Final concentration was 344 and $211 \mathrm{mBq} / \mathrm{mL}$ respectively. The ${ }^{239} \mathrm{Pu}$ solution was prepared as above where the final concentration was $333 \mathrm{mBq} / \mathrm{ml}$ in a solution of $0.08 \mathrm{M} \mathrm{HNO}_{3}$. Solutions were prepared to an acid concentration of $0.08 \mathrm{M} \mathrm{HNO}_{3}$. In addition, to nitric acid solutions a $0.1 \mathrm{~mL}$ of saturated sodium nitrite was added.

\subsection{Preparation of soil samples}

$1 \mathrm{~g}$ of a pre-analyzed soil was prepared to test potential interferences associated with analysis of a realistic sample. A soil sample that had been previously tested for actinide concentration was prepared by $\mathrm{NaOH}$ fusion. One gram of soil and 6 grams of $\mathrm{NaOH}$ were heated over a natural gas Bunsen burner. After liquefaction the flux was cooled and then dissolved in $50 \mathrm{~mL}$ water. The iron hydroxide precipitation that carries the actinides was filtered under vacuum and the solid was dissolved in a dilute nitric acid solution with $0.1 \mathrm{~mL}$ saturated solution of sodium nitrite. The acid solution was placed on a hot plate at $\sim 100{ }^{\circ} \mathrm{C}$ until dry. The solid residue was dissolved in $10 \mathrm{~mL} 0.08 \mathrm{M} \mathrm{HNO}_{3}$. From prior analysis this sample was shown to contain ${ }^{239} \mathrm{Pu}$ at a concentration of $4.2 \mathrm{~Bq}$ per gram, ${ }^{241} \mathrm{Am}$ at a concentration of $0.185 \mathrm{~Bq}$ per gram, and ${ }^{234 / 238} \mathrm{U}$ at a concentration of $0.26 \mathrm{~Bq}$ per isotope per gram.

\subsection{Analysis of PLFs}

The thin films were analyzed using a Quanta 200 FEG scanning electron microscope that was run in both environmental mode and low pressure to prevent any contamination from the organic material and by alpha spectroscopy using an Ortec Octete Plus spectrometer. Radioactive analytes were collected on the polymer ligand film by direct stippling of the prepared solution for $2 \mathrm{~h}$. The acid solution was removed from the planchet by rinsing with deionized water. The sample was then allowed to air dry. Once dry, the polymer ligand film was placed directly in the alpha spectrometer. Samples

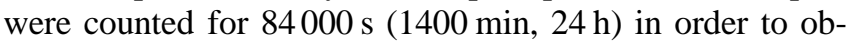
tain high quality counting statistics even with samples with low activity. This counting time allows for minimum detectable amounts of $0.83 \mathrm{mBq}$. A calibration standard was prepared using a comparable stainless steel disk onto which $1 \mathrm{~mL}$ each of ${ }^{242} \mathrm{Pu},{ }^{238} \mathrm{Pu}$, and ${ }^{239} \mathrm{Pu}$ NIST standards are added. The alpha spectrometer detector counting efficiencies are calculated from an average of the three isotopes, ${ }^{242} \mathrm{Pu}$, ${ }^{239} \mathrm{Pu}$, and ${ }^{238} \mathrm{Pu}$. Backgrounds are insignificant in the calibration calculations and are not subtracted. The sample was then submitted for scanning electron microscopy where specimens were analyzed using a spot size of 4.5 at $20 \mathrm{KV}$.

\section{Results and discussion}

\subsection{Preparation of polymer ligand films}

The preparation of the polymer ligand films was simple and straightforward. The two PLFs that were prepared on a stainless steel planchet (poly(styerene)/Dipex ${ }^{\circledR}$ and nitrocellulose/Dipex ${ }^{\circledR}$ ) were deposited directly on the surface and allowed to dry. The PLF that was prepared on a poly(propylene) filter (Poly(vinylpyrrolidone)/Dipex ${ }^{\circledR}$ ) was also directly deposited, but could take a smaller amount of the PLF due to the porous structure of the filter. Both methods were very straightforward and enabled a simple preparation method for the PLF surfaces.

\subsection{Extraction of plutonium and americium}

In order to test the polymer ligand films, extractions were performed utilizing plutonium and americium. For the two 

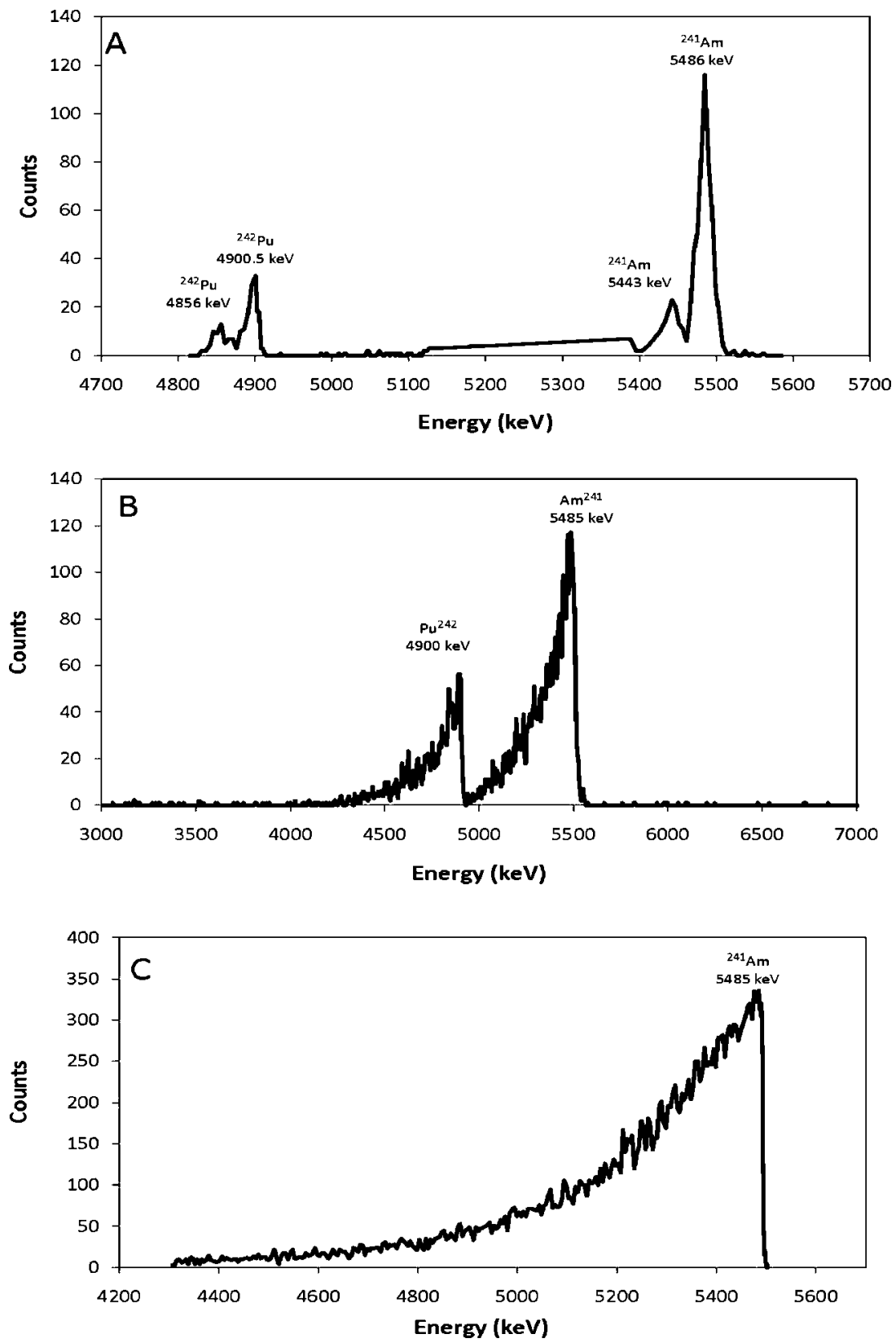

Fig. 1. Extraction of radionuclides from solution onto three polymer ligand films. (a) Extraction of $\mathrm{Pu}$ and $\mathrm{Am}$ onto poly(styrene)/Dipex ${ }^{\circledR} \mathrm{PLF}$. (b) Extraction of $\mathrm{Pu}$ and Am onto nitrocellulose/ Dipex ${ }^{\circledR}$ PLF. (c) Extraction of Am onto poly(vinylpyrrolidone)/Dipex ${ }^{\circledR}$ on poly(propylene) filter.
PLFs prepared on a planchet, the analyte was placed directly on the surface and allowed to equilibrate for $2 \mathrm{~h}$ after which time the radioactive solution was removed and the PLF was rinsed with deionized water. The alpha spectra for the three PLF surfaces are presented in Fig. 1. The extraction efficiency and the peak resolution at Full Width at Half of the Maximum for the selected peak heights (FWHM) are presented in Table 1. This data shows that the extraction efficiency for americium is very high for both the poly(styrene) and the nitrocellulose based PLF surfaces. The extraction of plutonium is significantly less on the poly(styrene) PLF, but is more than four times higher on the nitrocellulose based PLF. The peak widths for the poly(styrene) are very narrow, but nearly three times as wide for the nitrocellulose. The PLF prepared on the poly(propylene) filter extracted relatively little americium and also had a very broad peak. The width of this peak made the analysis of a second analyte impossible, thus only americium was studied. Because the results of the poly(styrene) based PLF were so good, we
Table 1. Percent recovery and FWHM for samples prepared using electroplating and three polymer ligand films.

\begin{tabular}{lccc}
\hline Sample & Analyte & \% recovery & FWHM (keV) \\
\hline Electroplated & $\mathrm{Pu}$ & 100 & 22 \\
& $\mathrm{Am}$ & 100 & 31 \\
\hline Poly(styrene) & $\mathrm{Pu}$ & 8 & 25 \\
& $\mathrm{Am}$ & 53 & 34 \\
\hline Nicrocellulose & $\mathrm{Pu}$ & 36 & 60 \\
\hline Filter & $\mathrm{Am}$ & 54 & 85 \\
\hline
\end{tabular}

compared these results to an electroplated sample (Fig. 2). The extraction efficiency of the electroplated sample was much higher than the PLF, but the FWHM of the peaks was nearly identical. This sample produced high enough reso- 


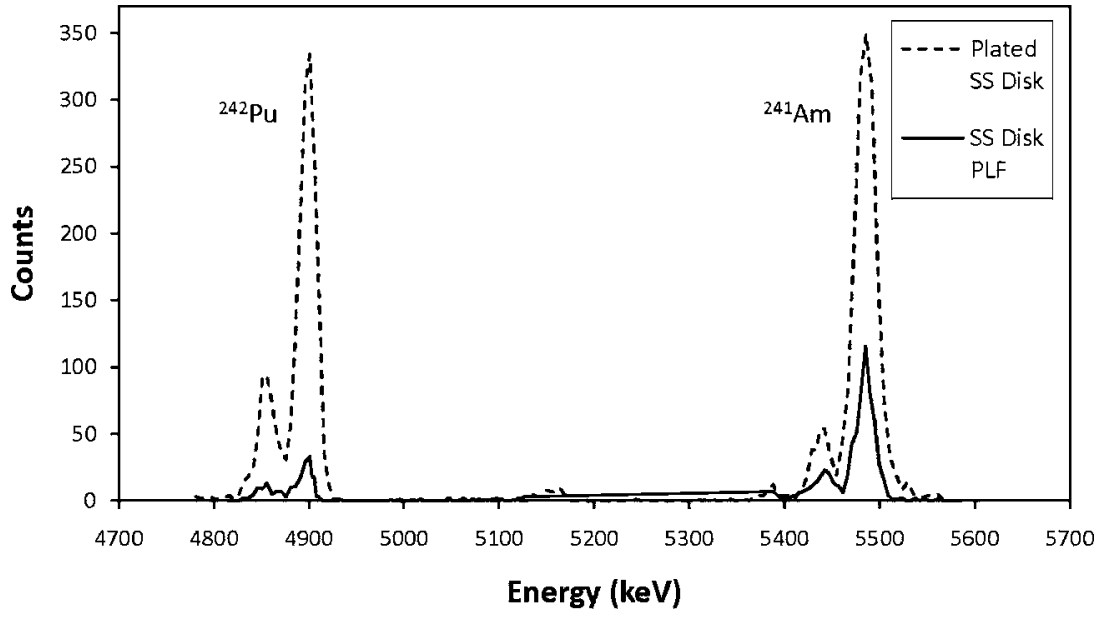

Fig. 2. Comparison between poly(styrene)/Dipex ${ }^{\circledR}$ PLF and electroplated sample. lution that the secondary alpha particles can be clearly identified in the spectrum.

\subsection{Analysis of vitrified glass sample}

To demonstrate the utility of this method in extracting actinides from a soil sample, which was prepared by molten salt fusion. The prepared sample was dissolved in nitric acid and placed onto the PLF to extract the analytes of interest prior to analysis. The utility was tested using a poly(styrene)/Dipex ${ }^{\circledR}$ and a nitrocellulose/Dipex ${ }^{\circledR}$ PLF surfaces. The resulting spectra are given in Fig. 3 and the extraction efficiencies and FWHM values are given in Table 2. These data show that both PLF surfaces extract a relatively small amount of the total sample from the solution. These low recoveries are likely a result of losses of the analyte due to a limited number of active sites on the PLF relative to the high concentration of other analytes present in this particular sample. The sample has both radiological and non-radiological interferences present. The peak widths for both samples are very good. The FWHM for the poly(styrene)/Dipex ${ }^{\circledR}$ PLF is near what can be expected
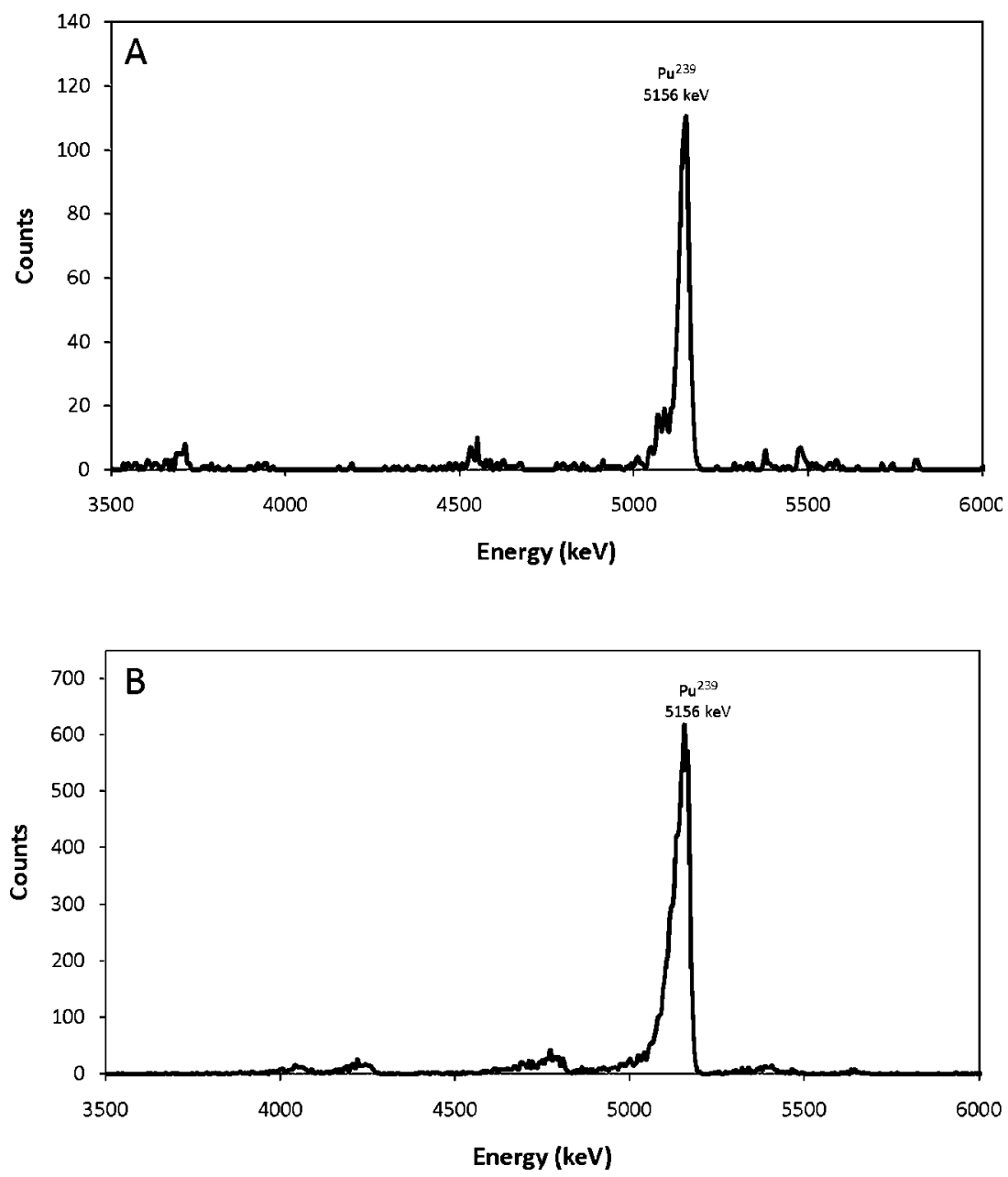

Fig. 3. Use of PLF for sample prepared from vitrified glass sample. (a) Poly(styrene)/Dipex ${ }^{\circledR}$ PLF. (b) Nitrocellulose/Dipex ${ }^{\circledR}$ PLF. 
Table 2. Percent recovery and FWHM for samples prepared from soil sample digested using a molten salt extraction technique.

\begin{tabular}{lccc}
\hline $\begin{array}{l}\text { Extraction } \\
\text { conditions }\end{array}$ & Analyte & Recovery (\%) & $\begin{array}{c}\text { FWHM } \\
(\mathrm{keV})\end{array}$ \\
\hline Poly(styrene) & $\mathrm{Pu}$ & 5 & 27 \\
Nitrocellulose & $\mathrm{Pu}$ & 7 & 60 \\
\hline
\end{tabular}

from a electroplated sample. The FWHM for the nitrocellulose is somewhat larger, but is actually better than what was observed for the preparation of the neat solution. This may be due to the occupation of active sites with non-radiological compounds, which causes the radioactive analytes to coagulate in discrete groups resulting in the improved quality of the data spectra. The presence of these compounds is greatly elevated in the soil sample, thus complicating the data interpretation.

\subsection{Scanning electron microscopy}

Because the three PLF surfaces gave very different analytical results, we also examined the three PLFs under an electron microscope to examine the microstructure of the surfaces. Fig. 4 shows the SEM for the three surfaces. Fig. 4a shows the SEM for the poly(styrene) based PLF, and it can be seen that discrete specks of the polymer is formed. This could explain the observation that this surface extracts relatively little analyte but with very high efficiency because the analyte is effectively concentrated into many point-sources on the surface. Conversely, the nitrocellulose based PLF (Fig. 4b) is nearly continuous and smooth. This may produce a large number of active sites to collect analytes on the surface, which also causes band broadening in the spectra. Finally, Fig. 4c shows the PLF prepared on the filter; and shows the characteristic filter structure. The penetration of the analyte into the filter produces very broad peaks as the alpha particles are attenuated upon exiting the filter.

\section{Conclusions}

We have demonstrated the production of polymer ligand films and their use to rapidly and efficiently extract plutonium and americium from solution. This has efficiencies as high as $54 \%$ for americium and $36 \%$ for plutonium. In addition, the quality of the data obtained has FWHM values as low as $25 \mathrm{keV}$ for plutonium and $34 \mathrm{keV}$ for americium; which is nearly as good as can be obtained with electroplated samples. The collection time that was required is $2 \mathrm{~h}$, which is very short compared to wet chemical methods. The quality of data for samples passed through a PLF filter is not as good as the prepared surfaces, particularly in respect to the FWHM values obtained. The preparation of the PLFs was done by simply depositing a solution containing the polymer and the extractant on a surface or filter and allowing it to dry. Further studies will examine the kinetics of extraction and the effects of other PLF parameters including thickness, selection of extractant, and other methods for preparing the PLFs such as spin coating or direct polymerization. We will also examine the uniformity of ligand distribution in the PLF and the microstructure. We will also examine the possibility

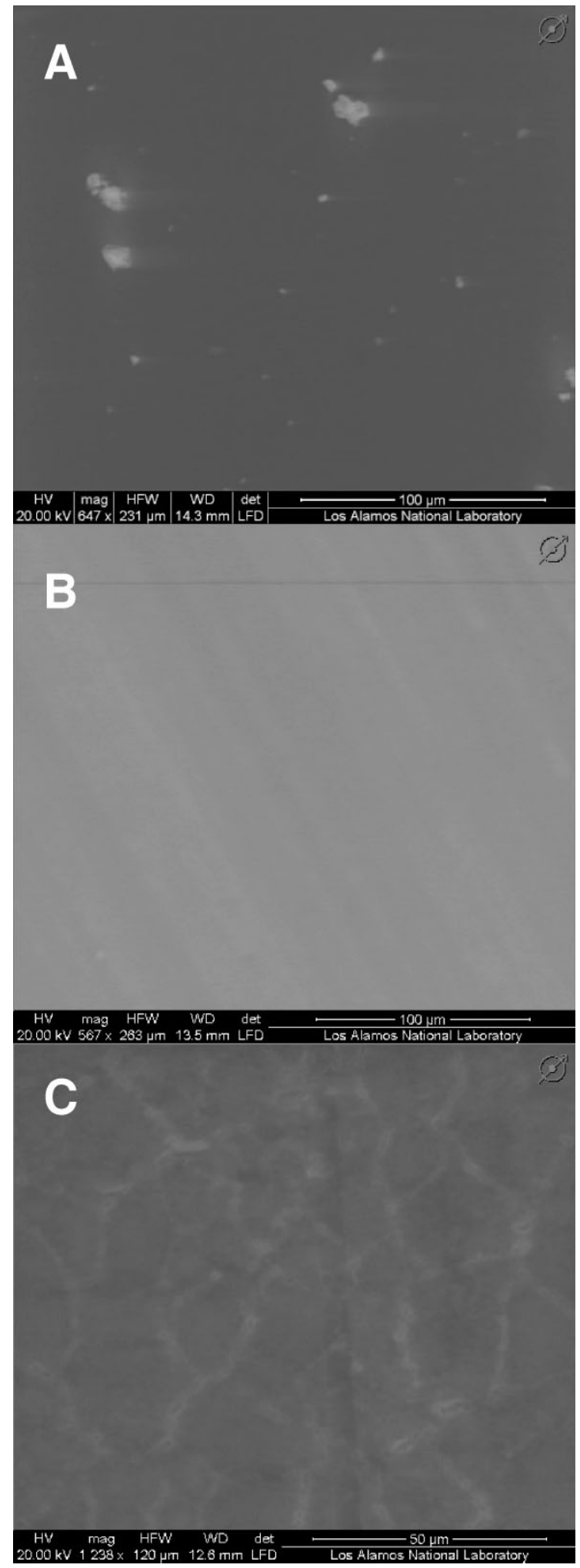

Fig. 4. SEM of PLF surfaces. (a) Poly(styrene)/Dipex ${ }^{\circledR}$; (b) nitrocellulose/Dipex ${ }^{\circledR}$; poly(vinylpyrrolidone)/Dipex ${ }^{\circledR}$ on poly(propylene) filter.

of selectively extracting one analyte over another in solution, including evaluating other extractive ligands.

Acknowledgment. The authors would like to thank Jaclyn Herrera for her assistance in preparing Figs. 1-3. Los Alamos National Laboratory is operated by Los Alamos National Security, LLC for the US Department of Energy under Contract number DE-AC52-06NA25396. 
Funding through the Department of Energy Office of Nuclear Nonproliferation Research and Development is gratefully acknowledged. This publication is LAUR-10-5211.

\section{References}

1. Choppin, G. R., Jensen, M. P.: Actinides in solution: complexation and kinetics. In: The Chemistry of the Actinide and Transactinide Elements. (Morss, L. R., Edelstein, N. M., Fuger, J., eds.) Vol. 4, Springer, Dordrecht (2006), pp. 2524-2621.

2. Grate, J. W., Egorov, O. B.: Automated radiochemical separation, analysis, and sensing. In: Handbook of Radioactivity Analysis. (L'Annunziata, M. F.) Elsevier, London (2003), pp. 1129-1164.

3. Nash, K. L., Madic, C., Mathur, J. N., Lacquement, J.: Actinide separation science and technology. In: The Chemistry of the Actinide and Transactinide Elements. (Morss, L. R., Edelstein, N. M., Fuger, J., eds.) Vol. 4, Springer, Dordrecht (2006), pp. 2622-2798.

4. Rosson, R.: Sample collection and preparation. In: Radioanalytical Chemistry. (Kahn, B., ed.) Springer, New York (2007), pp. 77-92.
5. Talvitie, N. A.: Anal. Chem. 44, 280 (1972).

6. Koulouridakis, P. E., Kallithrakas-Kontos, N. G.: Anal. Chem. 76, 4315-4319 (2004).

7. Graul, T. W., Li, M., Schlenoff, J. B.: J. Phys. Chem. B 103, 2718-2723 (1999).

8. Surbeck, H.: Appl. Radiat. Isotopes 53, 97-100 (2000).

9. Karamanis, D., Ioannides, K. G., Stamoulis, K. C.: Anal. Chim. Acta 573, 319-327 (2006).

10. Addleman, R. S., Egorov, O. B., O'Hara, M. J., Busche, B., Zemanian, T. S., Fryxell, G.: J. Radioanal. Nucl. Chem. 263, 59-64 (2005).

11. Oldham, W. J., Dry, D. E., Mueller, A. H.: J. Radioanal. Nucl. Chem. 282, 585-589 (2009).

12. Gonzales, E. R., Peterson, D. S.: J. Radioanal. Nucl. Chem. 282, 543-547 (2009).

13. Dam, H. H., Reinhoudt, D. N., Verboom, W.: Chem. Soc. Rev. 36, 367-377 (2007).

14. Mathur, J. N., Murali, M. S., Nash, K. L.: Solv. Extract. Ion Exchange 19, 357-390 (2001).

15. Horwitz, E. P., Chiarizia, R., Dietz, M. L.: React. Funct. Polym. 33, 25-36 (1997). 